\title{
Knowledge, Attitudes, and Practices Regarding Tuberculosis in Timor-Leste: Results From the Demographic and Health Survey 2016
}

\author{
Supa Pengpid ${ }^{1,2}$, Karl Peltzer $^{2}$ \\ ${ }^{7}$ ASEAN Institute for Health Development, Mahidol University, Salaya, Thailand; ' 2 Department of Research Administration and Development, \\ University of Limpopo, Turfloop Campus, Mankweng, South Africa
}

Objectives: The aim of this study was to assess knowledge, attitudes, and practices regarding tuberculosis (TB) in the general population in Timor-Leste.

Methods: In the nationally representative cross-sectional 2016 Timor-Leste Demographic and Health Survey, 4622 men (aged 15-59 years) and 12607 women (aged 15-49 years) were randomly selected using stratified multistage sampling and interviewed.

Results: Overall, $66.9 \%$ of men and $62.8 \%$ of women were aware of TB, $4.4 \%$ of men and $12.6 \%$ of women had TB courtesy stigma, and $83.3 \%$ of men and $88.6 \%$ of women reported intention to receive TB treatment. The mean \pm standard deviation overall TB knowledge score was $3.9 \pm 2.0$ (out of 8 ) among men and $3.0 \pm 1.8$ among women. In a multivariable linear regression analysis, among both men and women, older age, higher education, rural residence, and sources of TB information (family/friends, school/workplace, health care provider, Internet, television, and newspaper) were associated with higher TB knowledge scores. In addition, among women, higher wealth status and having heard about TB from the radio were associated with higher TB knowledge scores. Negative associations with TB courtesy stigma were found for urban residence and having heard about TB from family or friends among men, and for older age, higher TB knowledge, and TB information sources (family/friends and school/workplace) among women. Among both men and women, higher TB knowledge scores and having heard of TB from a health care provider were associated with intention to receive TB treatment.

Conclusions: This study identified socio-demographic risk factors for deficiences in population-based TB knowledge in Timor-Leste; these findings should be considered when designing TB communication, prevention, and control strategies.

Key words: Tuberculosis, Knowledge, Attitude, Timor-Leste

Received: July 24, 2018 Accepted: January 18, 2019

Corresponding author: Karl Peltzer, PhD Department of Research Administration and Development, University of Limpopo, Turfloop Campus, University Road, Mankweng 0727, South Africa

E-mail: kfpeltzer@gmail.com

This is an Open Access article distributed under the terms of the Creative Commons Attribution Non-Commercial License (http://creativecommons.org/licenses/bync/4.0// which permits unrestricted non-commercial use, distribution, and reproduction in any medium, provided the original work is properly cited.

\section{INTRODUCTION}

According to the World Health Organization (WHO), TimorLeste (with a population of 1.27 million) is a high-burden tuberculosis (TB) Southeast Asian country, with an incidence rate of 498 per 100000 , which is the sixth highest in the world; in contrast, the highest incidence is in Lesotho (665 per 100000 ), followed by South Africa (567 per 100 000) [1]. In Timor-Leste in 2016 , the TB case detection rate was $61.0 \%$ and the TB treat- 
ment success rate was $87.0 \%$ [1]. According to the Ministry of Health of Timor-Leste [2], "The high prevalence of TB is thought to be due to a combination of high poverty, low levels of literacy, low community awareness, insufficient access and poor health seeking with relatively poor use of health facilities and limited knowledge among the health staff for screening of TB in the health facilities as well as community." Timor-Leste has a 3-tiered government health system, including a national hospital, district hospitals, community health centres, health posts, and outreach centres [3]. In Timor-Leste, TB is the second most common cause of death in hospitals [2]. Barriers to accessing health services and treatment adherence include socioeconomic factors and other factors related to weak health systems [4].

In the Timor-Leste Demographic and Health Survey (TLDHS) $2009-2010,83.0 \%$ of men and $78.0 \%$ of women had ever heard of TB, $2.1 \%$ of men and $10.2 \%$ of women had TB courtesy stig$\mathrm{ma}$, and various TB knowledge deficiencies were identified [5]. In the 2011 Demographic and Health Survey (DHS) Ethiopia, $89.9 \%$ of women and $95.1 \%$ of men had heard of TB, and $27.9 \%$ of women and $18.7 \%$ of men had TB courtesy stigma [6]. Rood et al. [7] found that on average, TB courtesy stigma was reported by $25.6 \%$ of respondents in 13 countries. In the Thai population, the average TB knowledge score was 5.7 (maximum, 10) [8]. Regarding TB treatment behaviour, no information could be found on Timor-Leste. In a study in Vietnam, $83.0 \%$ of the general population stated that they would seek care from health care services if they suffered from a cough for more than 2 weeks [9].

Deficient TB knowledge and stigmatizing attitudes towards TB may lead to delays in the diagnosis and treatment of TB [10, 11]. TB knowledge and awareness of medical treatment are important for the success of TB prevention and control $[10,11]$. Various factors have been found to be associated with TB knowledge, stigma, and treatment, and understanding these factors is crucial for the implementation of TB prevention health education programmes. Agho et al. [12] found that higher wealth status, higher education, urban residence, and higher exposure to media sources were associated with having ever heard of TB. Factors associated with TB knowledge may include younger age $[9,12]$, men $[9,13]$, higher education [8], higher economic status [8,9], rural residence [12], and learning about TB from television, brochures, health workers, and teachers [14]. Factors negatively associated with TB courtesy stigma may include older age [7], men [15], higher wealth status [7], and TB knowledge [7]. Factors associated with intention to receive TB treatment may include higher education, higher economic status, and better TB knowledge $[16,17]$.

A five-year National TB Strategy was launched in January 2015 in Timor-Leste, including the training of all health workers on the new WHO protocol for drug regimens and treatment of TB and a focus on strengthening the diagnosis of the disease by improving the quality of laboratories and human resource capacity [18]. In addition, TB advocacy, communication, and social mobilization (ACSM) activities have been included, such as dissemination of ACSM materials through mass media (TV/local radio), TB messaging through billboards in urban areas, sensitization events involving village councils and other influence leaders, providing TB information in secondary schools, and training community volunteers on identifying individuals who may have TB [2]. Community messaging includes "if have a cough for more than 2 weeks, please come to the health centre for a TB sputum test, don't wait until the cough has blood. Even though TB is easy to transmit it is curable. Come to the community health centre and then get the treatment" [18]. In order to assess the progress of ACSM activities, we analysed knowledge, attitudes, and practices regarding TB in the general population from the 2016 TLDHS [19].

The aim of this study was to assess TB-related knowledge, attitudes, and practices in the general population in Timor-Leste.

\section{METHODS}

\section{Study Design and Participants}

Data from the 2016 TLDHS were analysed [19]. The 2016 TLDHS is a cross-sectional, nationally representative, population-based survey of 12607 women respondents aged 15-49 years and 4622 men respondents aged 15-59 years [19]. It is part of the design of the DHS to have a much larger sample of women than of men. The TLDHS employed a 2-stage (455 enumeration areas and 26 households per enumeration area) stratified sampling design [19]. Informed consent was obtained from study participants prior to the study. The 2016 TLDHS was approved by the Ethics Committee of Macro International Inc. and the Ministry of Health of Timor-Leste [19]. Permission to use the TLDHS data in this analysis was obtained from Opinion Research Corporation Macro Inc.

\section{Measures}

Socio-demographic variables included age, gender, formal education, wealth status, and residence [19]. TB awareness 
was investigated by asking the question, "Have you ever heard of an illness called tuberculosis or TB?" (yes, no) [19]. Sources of TB information were investigated by asking the question, "Where did you hear about tuberculosis or TB?" (family/friends, school/workplace, health care provider, television, radio, newspaper, and Internet) [19]. TB attitudes or stigma was assessed with the question, "If a member of your family got tuberculosis, would you want it to remain a secret or not? (yes, no, do not know) [19]. TB knowledge was assessed with 16 questions: 4 related to the cause of TB, 6 related to the transmission of TB, and 6 items related to TB symptoms (Cronbach alpha 0.70 for women and 0.68 for men). The correct responses were summed to give a total TB knowledge score. Intention to receive TB treatment was assessed with 2 hypothetical questions: (1) "If you have a cough for more than 2 weeks, would you seek treatment?" (2) "Where would you seek treatment for a cough lasting more than 2 weeks?" Respondents who responded "yes" to the first question and stated that they

Table 1. Sample characteristics and tuberculosis (TB) knowledge score by gender, Timor-Leste 2016

\begin{tabular}{|c|c|c|c|c|}
\hline \multirow{2}{*}{ Characteristics } & \multicolumn{2}{|c|}{ Sample } & \multicolumn{2}{|c|}{ TB knowledge score } \\
\hline & Men $(n=4622)$ & Women $(n=12$ 607) & Men $(n=3020)$ & Women $(n=8058)$ \\
\hline \multicolumn{5}{|l|}{ Socio-demographic factor } \\
\hline \multicolumn{5}{|l|}{ Age (y) } \\
\hline $15-24$ & $36.6(34.9,38.3)$ & $40.8(39.8,41.9)$ & $3.9 \pm 2.0$ & $2.9 \pm 1.6$ \\
\hline $25-34$ & $23.7(22.2,25.3)$ & $30.0(29.0,31.0)$ & $4.2 \pm 2.0$ & $3.0 \pm 1.5$ \\
\hline $35-49$ & $27.9(26.4,29.5)$ & $29.1(28.2,30.1)$ & $4.2 \pm 2.0$ & $3.2 \pm 1.6$ \\
\hline $50-59$ & $11.8(10.8,13.0)$ & - & $4.3 \pm 2.4$ & - \\
\hline \multicolumn{5}{|l|}{ Education } \\
\hline None & $22.7(21.3,24.2)$ & $21.7(20.8,22.7)$ & $3.8 \pm 2.0$ & $2.8 \pm 1.5$ \\
\hline Primary & $19.0(17.7,20.4)$ & $15.2(14.5,16.0)$ & $3.9 \pm 2.1$ & $2.8 \pm 1.6$ \\
\hline Secondary & $46.7(44.9,48.4)$ & $52.0(50.9,53.2)$ & $4.1 \pm 2.0$ & $3.0 \pm 1.6$ \\
\hline Post-secondary & $11.6(10.4,12.8)$ & $11.0(10.1,11.9)$ & $4.5 \pm 1.9$ & $3.2 \pm 1.6$ \\
\hline \multicolumn{5}{|l|}{ Wealth quintile } \\
\hline Lowest & $16.4(15.2,17.7)$ & $16.5(15.6,17.5)$ & $4.2 \pm 2.0$ & $2.6 \pm 1.6$ \\
\hline Second & $20.7(19.4,22.1)$ & $18.1(17.2,19.2)$ & $4.1 \pm 1.9$ & $2.8 \pm 1.4$ \\
\hline Middle & $20.3(18.9,21.7)$ & $19.2(18.2,20.3)$ & $4.0 \pm 1.9$ & $2.7 \pm 1.5$ \\
\hline Fourth & $20.6(19.3,22.1)$ & $22.0(20.7,23.3)$ & $4.1 \pm 2.1$ & $3.1 \pm 1.9$ \\
\hline Highest & $22.0(20.4,23.6)$ & $24.1(22.7,25.6)$ & $4.1 \pm 2.0$ & $2.8 \pm 1.5$ \\
\hline \multicolumn{5}{|l|}{ Residence } \\
\hline Rural & $68.1(66.4,69.9)$ & $66.8(65.3,68.4)$ & $4.2 \pm 2.0$ & $2.8 \pm 1.6$ \\
\hline Urban & $31.9(30.1,33.6)$ & $33.2(31.6,34.7)$ & $3.8 \pm 2.0$ & $2.6 \pm 1.5$ \\
\hline \multicolumn{5}{|l|}{ TB knowledge } \\
\hline Overall & & & $3.9 \pm 2.0$ & $3.0 \pm 1.8$ \\
\hline Awareness of TB & $66.9(65.3,68.5)$ & $62.8(61.6,64.0)$ & - & - \\
\hline TB attitudes/stigma & $4.4(3.6,5.3)$ & $12.6(11.6,13.6)$ & $3.6 \pm 1.9$ & $2.5 \pm 1.5$ \\
\hline Intention to receive TB treatment & $83.3(82.7,84.8)$ & $88.6(87.5,89.7)$ & $4.2 \pm 2.0$ & $3.0 \pm 1.6$ \\
\hline \multicolumn{5}{|l|}{ Sources of TB information } \\
\hline Family/friends & $58.8(56.6,60.9)$ & $59.9(38.6,41.5)$ & $4.5 \pm 2.0$ & $2.8 \pm 1.6$ \\
\hline School/workplace & $30.0(28.1,32.0)$ & $24.2(22.9,25.5)$ & $4.8 \pm 2.0$ & $3.4 \pm 1.6$ \\
\hline Health care provider & $53.6(51.4,55.8)$ & $47.2(45.6,48.7)$ & $4.4 \pm 2.0$ & $3.1 \pm 1.7$ \\
\hline Internet & $5.0(4.1,6.1)$ & $3.8(3.3,4.4)$ & $6.1 \pm 2.1$ & $2.8 \pm 1.6$ \\
\hline Television & $28.1(26.1,30.1)$ & $13.2(12.1,14.4)$ & $4.8 \pm 2.2$ & $2.9 \pm 1.5$ \\
\hline Radio & $17.0(15.4,18.7)$ & $7.3(6.6,8.2)$ & $5.0 \pm 2.1$ & $3.0 \pm 1.3$ \\
\hline Newspaper & $5.9(4.9,6.9)$ & $1.8(1.4,2.3)$ & $5.8 \pm 2.0$ & $3.5 \pm 1.5$ \\
\hline
\end{tabular}

Values are presented as \% (95\% confidence interval) or mean \pm stanadard deviation. 
would seek treatment at a health facility were coded as intending to receive TB treatment [19].

\section{Data Analysis}

Data analysis was performed with Stata version 13.0 (StataCorp., College Station, TX, USA) considering the multistage study design. The sample was described using descriptive statistics. A multivariable linear regression analysis was conducted between the independent variables and the TB knowledge score, for men and women separately. Logistic regression analyses were performed between independent variables and 3 dependent variables (TB awareness, stigmatizing attitudes towards $\mathrm{TB}$, and intention to receive TB treatment). The $p$-values $<0.05$ were considered to indicate statistical significance.

\section{RESULTS}

\section{Sample Characteristics}

The sample of the general population included 4622 men (aged 15-59 years), of whom 3020 were aware of TB, and 12607 women (aged 15-49 years), of whom 8058 were aware of TB. The response rate was $95.0 \%$ for men and $97.0 \%$ for women. Overall, $66.9 \%$ of men and $62.8 \%$ of women were aware of TB, $4.4 \%$ of men and $12.6 \%$ of women had stigmatizing attitudes towards TB, and $83.3 \%$ of men and $88.6 \%$ of women intended

Table 2. Associations with awareness of TB and TB knowledge score ${ }^{1}$

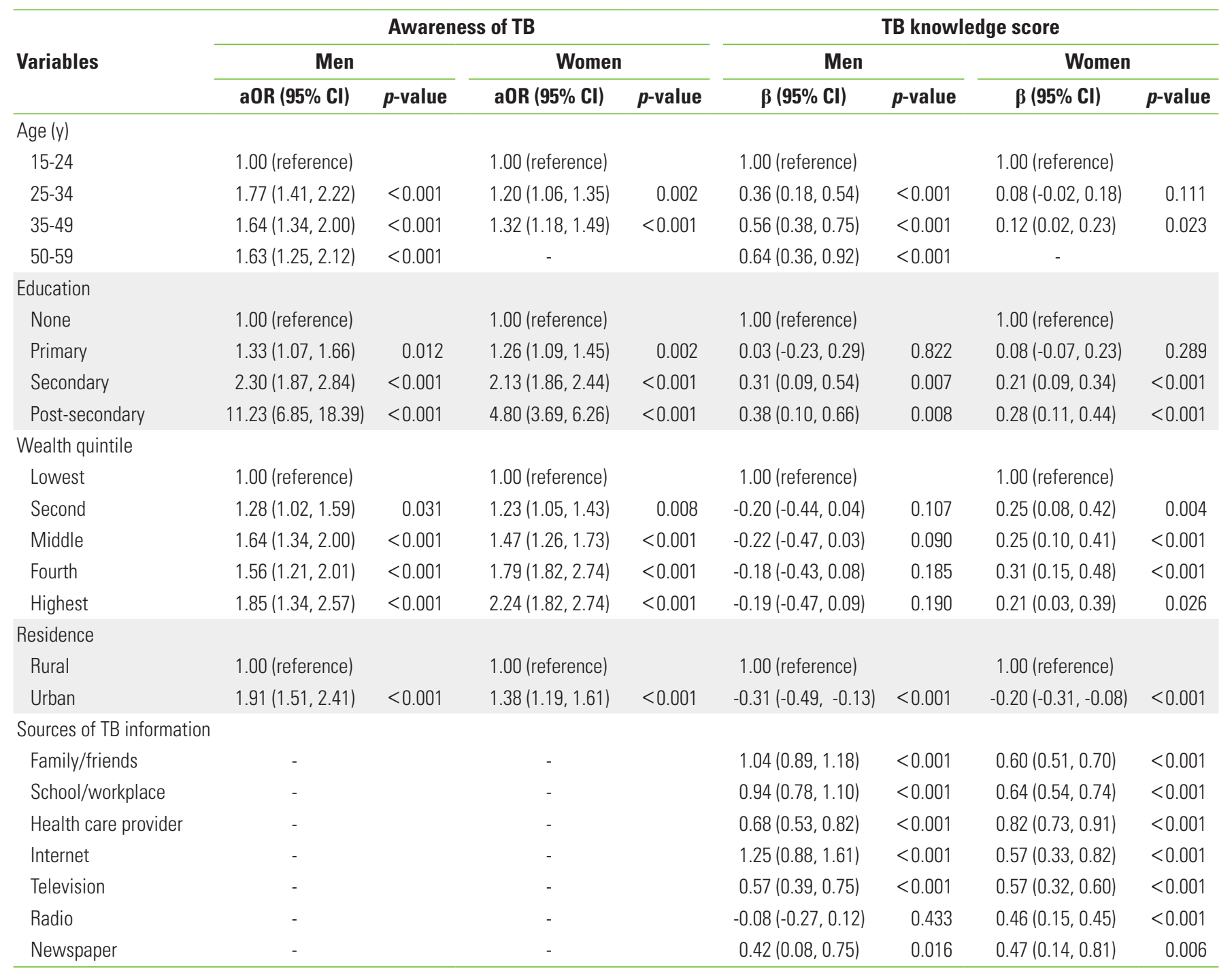

aOR, adjusted odds ratio; $\mathrm{Cl}$, confidence interval.

${ }^{1}$ Adjusted for all variables in the table. 
to receive TB treatment. The mean \pm standard deviation overall TB knowledge score was 3.9 \pm 2.0 among men and 3.0 \pm 1.8 among women, out of a possible score of 8 . The most common source of TB information was family and friends for men and women, followed by a health care provider, school or workplace, television, radio, Internet, and newspapers (Table 1).

\section{Associations With Awareness of Tuberculosis}

\section{(TB) and TB Knowledge Score}

In the multivarible logistic regression analysis, among both men and women, older age (odds ratio [OR],1.63; 95\% confi- dence interval [Cl], 1.25 to $2.12 ; \mathrm{OR}, 1.32 ; 95 \% \mathrm{Cl}, 1.18$ to 1.49 for men and women, respectively), higher levels of education (OR, 11.23; $95 \% \mathrm{Cl}, 6.85$ to $18.39 ; \mathrm{OR}, 4.80 ; 95 \% \mathrm{Cl}, 3.69$ to 6.26 , respectively), higher wealth status $(\mathrm{OR}, 1.85 ; 95 \% \mathrm{Cl}, 1.34$ to 2.57; OR, 2.24; $95 \% \mathrm{Cl}, 1.82$ to 2.74 , respectively), and urban residence (OR, $1.91 ; 95 \% \mathrm{Cl}, 1.51$ to $2.41 ; \mathrm{OR}, 1.38 ; 95 \% \mathrm{Cl}, 1.19$ to 1.61 , respectively) were associated with TB awareness. In the multivariable linear regression analysis, among both men and women, older age $(\beta, 0.64 ; 95 \% \mathrm{Cl}, 0.36$ to $0.92 ; \beta, 0.12$; $95 \% \mathrm{Cl}, 0.02$ to 0.23 , for men and women, respectively), higher education ( $\beta, 0.38 ; 95 \% \mathrm{Cl}, 0.10$ to $0.66 ; \beta, 0.28 ; 95 \% \mathrm{Cl}, 0.11$ to

Table 3. Associations with TB attitude/stigma and intention to receive TB treatment ${ }^{1}$

\begin{tabular}{|c|c|c|c|c|c|c|c|c|}
\hline \multirow{3}{*}{ Variable } & \multicolumn{4}{|c|}{ TB attitude/stigma } & \multicolumn{4}{|c|}{ Intention to receive TB treatment } \\
\hline & \multicolumn{2}{|l|}{ Men } & \multicolumn{2}{|l|}{ Women } & \multicolumn{2}{|l|}{ Men } & \multicolumn{2}{|c|}{ Women } \\
\hline & aOR $(95 \% \mathrm{CI})$ & $p$-value & aOR (95\% Cl) & $p$-value & aOR $(95 \%$ CI) & $p$-value & aOR $(95 \% \mathrm{Cl})$ & $p$-value \\
\hline \multicolumn{9}{|l|}{ Age (y) } \\
\hline $15-24$ & 1.00 (reference) & & 1.00 (reference) & & 1.00 (reference) & & 1.00 (reference) & \\
\hline $25-34$ & $0.85(0.51,1.44)$ & 0.553 & $0.74(0.61,0.91)$ & 0.003 & $1.24(0.90,1.69)$ & 0.182 & $1.08(0.87,1.34)$ & 0.485 \\
\hline $35-49$ & $1.02(0.63,1.66)$ & 0.922 & $0.82(0.67,0.99)$ & 0.043 & $1.35(0.99,1.84)$ & 0.059 & $1.24(0.98,1.57)$ & 0.076 \\
\hline $50-59$ & $0.71(0.32,1.60)$ & 0.424 & - & & $1.17(0.76,1.81)$ & 0.468 & - & \\
\hline \multicolumn{9}{|l|}{ Education } \\
\hline None & 1.00 (reference) & & 1.00 (reference) & & 1.00 (reference) & & 1.00 (reference) & \\
\hline Primary & $0.87(0.44,1.71)$ & 0.680 & $0.95(0.73,1.25)$ & 0.727 & $0.90(0.62,1.32)$ & 0.607 & $0.98(0.68,1.41)$ & 0.911 \\
\hline Secondary & $1.16(0.65,2.04)$ & 0.616 & $1.11(0.67,1.35)$ & 0.402 & $0.95(0.68,1.33)$ & 0.768 & $1.31(0.91,1.88)$ & 0.140 \\
\hline Post-secondary & $0.82(0.34,1.99)$ & 0.664 & $0.95(0.67,1.35)$ & 0.778 & $0.93(0.58,1.50)$ & 0.771 & $1.59(0.99,2.55)$ & 0.052 \\
\hline \multicolumn{9}{|l|}{ Wealth quintile } \\
\hline Lowest & 1.00 (reference) & & 1.00 (reference) & & 1.00 (reference) & & 1.00 (reference) & \\
\hline Second & $1.56(0.77,3.17)$ & 0.218 & $1.51(1.09,2.09)$ & 0.013 & $1.14(0.80,1.62)$ & 0.482 & $0.78(0.56,1.08)$ & 0.138 \\
\hline Middle & $0.73(0.34,1.58)$ & 0.424 & $1.35(0.99,1.83)$ & 0.057 & $1.39(0.94,2.05)$ & 0.098 & $0.86(0.57,1.25)$ & 0.450 \\
\hline Fourth & $0.54(0.23,1.24)$ & 0.146 & $1.05(0.76,1.46)$ & 0.749 & $0.93(0.63,1.35)$ & 0.689 & $0.73(0.53,1.03)$ & 0.070 \\
\hline Highest & $0.59(0.23,1.50)$ & 0.266 & $0.90(0.63,1.30)$ & 0.570 & $1.24(0.70,2.00)$ & 0.373 & $1.07(0.72,1.57)$ & 0.750 \\
\hline \multicolumn{9}{|l|}{ Residence } \\
\hline Rural & 1.00 (reference) & & 1.00 (reference) & & 1.00 (reference) & & 1.00 (reference) & \\
\hline Urban & $0.54(0.32,0.93)$ & 0.025 & $0.95(0.74,1.20)$ & 0.646 & $2.33(1.68,3.23)$ & $<0.001$ & $0.68(0.49,0.94)$ & 0.020 \\
\hline TB knowledge & $0.97(0.87,1.08)$ & 0.604 & $0.75(0.71,0.80)$ & $<0.001$ & $1.19(1.11,1.28)$ & $<0.001$ & $1.28(1.14,1.30)$ & $<0.001$ \\
\hline TB attitudes/stigma & - & & - & - & $1.36(0.78,2.35)$ & 0.280 & $0.68(0.54,0.85)$ & $<0.001$ \\
\hline \multicolumn{9}{|c|}{ Sources of TB information } \\
\hline Family/friends & $0.33(0.20,0.55)$ & $<0.001$ & $0.67(0.56,0.82)$ & $<0.001$ & $0.97(0.75,1.25)$ & 0.797 & $1.47(1.19,1.82)$ & $<0.001$ \\
\hline School/workplace & $0.71(0.43,1.16)$ & 0.170 & $0.70(0.55,0.88)$ & 0.003 & $1.52(1.13,2.04)$ & 0.006 & $1.01(0.80,1.28)$ & 0.910 \\
\hline Health care provider & $0.68(0.43,1.06)$ & 0.090 & $1.18(0.98,1.43)$ & 0.087 & $1.66(1.29,2.15)$ & $<0.001$ & $1.61(1.30,2.02)$ & $<0.001$ \\
\hline Internet & $0.83(0.25,2.81)$ & 0.766 & $0.75(0.43,1.31)$ & 0.311 & $0.81(0.36,1.79)$ & 0.596 & $1.16(0.66,2.04)$ & 0.604 \\
\hline Television & $0.69(0.38,1.26)$ & 0.227 & $1.05(0.79,1.38)$ & 0.749 & $2.19(1.51,3.18)$ & $<0.001$ & $1.31(0.91,1.89)$ & 0.143 \\
\hline Radio & $0.56(0.29,1.07)$ & 0.081 & $0.72(0.50,1.03)$ & 0.074 & $1.42(0.98,2.04)$ & 0.060 & $1.46(0.98,2.16)$ & 0.060 \\
\hline Newspaper & $1.88(0.81,4.33)$ & 0.139 & $0.60(0.26,1.38)$ & 0.229 & $0.62(0.31,1.24)$ & 0.175 & $0.76(0.36,1.61)$ & 0.469 \\
\hline
\end{tabular}

aOR, adjusted odds ratio; $\mathrm{Cl}$, confidence interval.

${ }^{1}$ Adjusted for all variables in the table. 
0.44 , respectively), urban residence $(\beta,-0.31 ; 95 \% \mathrm{Cl},-0.49$ to $-0.13 ; \beta,-0.20 ; 95 \% \mathrm{Cl},-0.31$ to -0.08 , respectively), and sources of TB information (family/friends, school/workplace, health care provider, Internet, television, and newspaper) were associated with higher TB knowledge scores. In addition, among women, higher wealth status $(\beta, 0.21 ; 95 \% \mathrm{Cl}, 0.03$ to 0.39$)$ and hearing about TB from the radio were associated with higher TB knowledge scores (Table 2).

\section{Associations With Tuberculosis (TB) Courtesy Stigma and TB Treatment}

In the multivariable logistic regression analysis, among men, urban residence (OR, $0.54 ; 95 \% \mathrm{Cl}, 0.32$ to 0.93 ) and hearing about TB from family or friends (OR, $0.33 ; 95 \% \mathrm{Cl}, 0.20$ to 0.55$)$ were negatively associated with TB courtesy stigma. Among women, older age $(\mathrm{OR}, 0.82 ; 95 \% \mathrm{Cl}, 0.67$ to 0.99$)$, higher TB knowledge (OR, $0.75 ; 95 \% \mathrm{Cl}, 0.71$ to 0.80$)$, and TB information sources (family/friends and school/workplace), were negatively associated with TB courtesy stigma.

In the multivariable logistic regression analysis, among both men and women, higher TB knowledge scores (OR, 1.19; 95\% $\mathrm{Cl}, 1.11$ to $1.28 ; \mathrm{OR}, 1.28 ; 95 \% \mathrm{Cl}, 1.14$ to 1.30 , respectively), and having heard of TB from a health care provider (OR, 1.66; $95 \% \mathrm{Cl}, 1.29$ to $2.15 ; \mathrm{OR}, 1.61 ; 95 \% \mathrm{Cl}, 1.30$ to 2.02 , respectively) were associated with intention to receive TB treatment. In addition, among men, urban residence $(\mathrm{OR}, 2.33 ; 95 \% \mathrm{Cl}, 1.68$ to 3.23) was positively associated with intention to receive $T B$ treatment, while among women, urban residence $(\mathrm{OR}, 0.68$; $95 \% \mathrm{Cl}, 0.49$ to 0.94$)$ and stigamtizing attitudes towards TB (OR, $0.68 ; 95 \% \mathrm{Cl}, 0.54$ to 0.85 ) were negatively associated with intention to receive TB treatment. Further, sources of information about TB (school/workplace and television for men; family/friends for women) were associated with intention to receive TB treatment (Table 3 ).

\section{DISCUSSION}

In the nationally representative 2016 TLDHS in Timor-Leste, poor TB knowledge was identified. Only $66.9 \%$ of men and $62.8 \%$ of women were aware of TB, reflecting a decrease from the $2009-2010$ TLDHS, in which $83.0 \%$ of men and $78.0 \%$ of women were aware of TB [5]. This proportion was lower than, for example, the findings of the 2011 DHS Ethiopia, in which $89.9 \%$ of women and $95.1 \%$ of men had heard of TB [6]. The mean overall TB knowledge score was low $(3.9 \pm 2.0$ among men and 3.0 \pm 1.8 among women, out of a maximum score of 8). This score was lower than that reported in a study in Thailand (5.7 of 10 points) [8]. It appears that ACSM activities, such as dissemination of ACSM materials through mass media (only $28.1 \%$ of men and $13.2 \%$ of women had heard about TB from the TV and $13.2 \%$ of men and $7.3 \%$ from the local radio), did not reach certain communities, resulting in an even lower TB awareness in 2016 than in 2009-2010. The study found low TB courtesy stigma ( $4.4 \%$ of men and $12.6 \%$ of women), which is similar to the findings of the 2009-2010 TLDHS (2.1\% of men and $10.2 \%$ among women) [5], and much lower than was reported in another study of participants from 13 countries (25.6\%) [7]. Intention to receive TB treatment was $83.3 \%$ among men and $88.6 \%$ among women in this study; these values are somewhat higher than the finding of a study in Vietnam (83.0\%) [9]. Given that the ACSM in Timor-Leste included community sensitization on TB treatment-seeking [18], it is possible that the high rate of intention to receive TB treatment can be attributed to ACSM. The sources of TB information in this study were similar to those reported by other surveys in the region $[8,9]$. However, in Thailand and Vietnam [6,7], TV, radio, and Internet were much more prominent sources of information on TB than in this study. This may be because of the lack of penetration of telecommunications to the general population in Timor-Leste. The most commonly reported sources of information about TB in our study were family or friends and health care providers, meaning that these ways of delivering or sharing TB information should be strengthened. In addition, schools and workplaces continued to play an insufficient role as sources of information about TB, suggesting that their roles should be strengthened. TB education for the public needs to achieve broad dissemination through multimedia and other channels in order to continue TB control improvement [20].

This study found that older age, higher levels of education, higher wealth status, and urban residence were associated with TB awareness. Similar results were found in a study in Nigeria [11]. Possible reasons for this finding include better media access to TB information [11]. Consistent with previous studies [8,11-14], this study found that men, higher education, higher wealth status, rural residence, and various sources of TB information, including family/friends, school/workplace, health care providers, Internet, radio, television and newspaper, were associated with higher TB knowledge scores. It is possible that among rural dwellers who were aware of $\mathrm{TB}$, the ACSM community sensitization on TB treatment-seeking [18] contributed to better TB knowl- 
edge scores. Contrary to previous studies [11,12], this study found that older age was associated with higher TB knowledge. In agreement with previous studies $[7,15]$, this study found that older age, men, and higher TB knowledge were negatively associated with TB courtesy stigma. Consistent with previous research $[8,16,17]$, this study found that higher TB knowledge and lower TB stigma were associated with intention to receive TB treatment at a health facility. Fear of TB stigma among women and poor TB knowledge may delay the diagnosis of TB, which should be addressed in health education [12]. ACSM activities should help reduce social stigma by reinforcing the belief that TB is curable and improving TB knowledge among the general population [20].

A limitation of this study is that it had a cross-sectional design, so no causal conclusions can be drawn. Further, stigmatizing attitudes towards TB were only measured with a single question and intention to receive TB treatment was only assessed with 2 hypothetical questions. There was a large sample size difference between men and women in this survey, which may suggest certain limitations. Future studies should include multi-item measures of TB attitude or stigma and direct questions on TB treatment behaviour.

In conclusion, the results showed an overall below medium level of TB knowledge, low levels of TB courtesy stigma, and moderately high intentions to receive TB treatment at a health facility. Efforts to improve knowledge, attitudes, and treatment intention regarding TB in Timor-Leste should focus on women, younger and older age groups, those with poorer wealth status, and those with less formal education. In order to increase early TB health care-seeking behaviour, TB knowledge among the general population needs to be increased. Health education activities need to strengthened using effective multimedia-based ACSM reaching the whole population. Early health care-seeking behaviour may reduce the incidence of TB, thereby helping Timor-Leste to achieve the Millennium Development Goal 6. Similar studies need to be conducted in order to assess and monitor changes in TB knowledge, attitudes, and practices in response to the Timor-Leste TB control and prevention programme.

\section{CONFLICT OF INTEREST}

The authors have no conflicts of interest associated with the material presented in this paper.

\section{ACKNOWLEDGEMENTS}

The authors thank the DHS Program Demographic and Health Surveys for the data used in this study.

\section{ORCID}

\section{Supa Pengpid https://orcid.org/0000-0002-7714-8869 \\ Karl Peltzer https://orcid.org/0000-0002-5980-0876}

\section{REFERENCES}

1. World Health Organization. Global tuberculosis report 2018 [cited 2019 Jan 10]. Available from: https://www.who.int/tb/ publications/global_report/en/.

2. Global Fund. Timor-Leste: overview; 2014 [cited 2018 May 5]. Available from: https://www.theglobalfund.org/en/portfolio/ country/?loc $=$ TLS\&k=9da0b8b2-7521-4c14-ab9a-7f1140e5247a.

3. Hou X, Witter S, Zaman RU, Engelhardt K, Hafidz F, Julia F, et al. What do health workers in Timor-Leste want, know and do? Findings from a national health labour market survey. Hum Resour Health 2016;14(1):69.

4. Price JA, Soares Al, Asante AD, Martins JS, Williams K, Wiseman VL. "I go I die, I stay I die, better to stay and die in my house": understanding the barriers to accessing health care in TimorLeste. BMC Health Serv Res 2016;16(1):535.

5. National Statistics Directorate, Ministry of Finance. Timor-Leste Demographic and Health Survey 2009-10; 2010 [cited 2019 Jan 10]. Available from: https://dhsprogram.com/pubs/pdf/ FR235/FR235.pdf.

6. Gelaw SM. Socioeconomic factors associated with knowledge on tuberculosis among adults in Ethiopia. Tuberc Res Treat 2016;2016:6207457.

7. Rood EJJ, Mergenthaler C, Bakker MI, Redwood L, Mitchell EM. Using 15 DHS surveys to study epidemiological correlates of TB courtesy stigma and health-seeking behaviour. Int J Tuberc Lung Dis 2017;21(11):60-68.

8. Pengpid S, Peltzer K, Puckpinyo A, Tiraphat S, Viripiromgool S, Apidechkul T, et al. Knowledge, attitudes, and practices about tuberculosis and choice of communication channels in Thailand. J Infect Dev Ctries 2016;10(7):694-703.

9. Hoa NP, Chuc NT, Thorson A. Knowledge, attitudes, and practices about tuberculosis and choice of communication channels in a rural community in Vietnam. Health Policy 2009;90(1): 
8-12.

10. Storla DG, Yimer S, Bjune GA. A systematic review of delay in the diagnosis and treatment of tuberculosis. BMC Public Health 2008;8:15.

11. Nichter M. Illness semantics and international health: the weak lungs/TB complex in the Philippines. Soc Sci Med 1994;38(5): 649-663.

12. Agho KE, Hall J, Ewald B. Determinants of the knowledge of and attitude towards tuberculosis in Nigeria. J Health Popul Nutr 2014;32(3):520-538.

13. Sreeramareddy CT, Harsha Kumar HN, Arokiasamy JT. Prevalence of self-reported tuberculosis, knowledge about tuberculosis transmission and its determinants among adults in India: results from a nation-wide cross-sectional household survey. BMC Infect Dis 2013;13:16.

14. Naidoo P, Simbayi L, Labadarios D, Ntsepe Y, Bikitsha N, Khan G, et al. Predictors of knowledge about tuberculosis: results from SANHANES I, a national, cross-sectional household survey in South Africa. BMC Public Health 2016;16:276.

15. Amo-Adjei J. Individual, household and community level factors associated with keeping tuberculosis status secret in Gha- na. BMC Public Health 2016;16(1):1196.

16. Mushtaq MU, Majrooh MA, Ahmad W, Rizwan M, Luqman MQ, Aslam MJ, et al. Knowledge, attitudes and practices regarding tuberculosis in two districts of Punjab, Pakistan. Int J Tuberc Lung Dis 2010;14(3):303-310.

17. Portero NJ, Rubio YM, Pasicatan MA. Socio-economic determinants of knowledge and attitudes about tuberculosis among the general population of Metro Manila, Philippines. Int J Tuberc Lung Dis 2002;6(4):301-306.

18. World Health Organization. Strengthening TB prevention and control in Timor-Leste; 2014 [cited 2018 Jun 12]. Available from: http://origin.searo.who.int/timorleste/mediacentre/ strengthening_tb_prevention_control.pdf.

19. General Directortate of Statistics. Timor-Leste Demography and Health Survey 2016; 2018 [cited 2018 Jun 10]. Available from: https://dhsprogram.com/pubs/pdf/FR329/FR329.pdf.

20. Ma E, Ren L, Wang W, Takahashi H, Wagatsuma Y, Ren Y, et al. Demographic and socioeconomic disparity in knowledge about tuberculosis in Inner Mongolia, China. J Epidemiol $2015 ; 25(4): 312-320$ 